\title{
Granulomatous angiitis of the central nervous system: protean manifestations and response to treatment
}

\author{
EDWARD H KOO,* E WAYNE MASSEY, $\dagger$ \\ From the Department of Neurology, University of California School of Medicine, ${ }^{*}$ San Francisco, CA and the \\ Division of Neurology, Duke University School of Medicine, Durham, NC, USA
}

SUMMARY Granulomatous angiitis is an uncommon necrotising vasculitis of unknown cause restricted to vessels of the central nervous system. Five tissue-proven cases emphasise the protean manifestations of this disease and the difficulties encountered in reaching a diagnosis. One patient presented with a temporoparietal mass, the second, a progressive dementia, the third suggested herpes simplex encephalitis, the fourth mimicked multi-infarct state; and the fifth presented with a cerebellar mass lesion. In four cases with CSF examination, protein was elevated (81-193 gm/1) and three patients had mononuclear pleocytosis $\left(12-800 \mathrm{WBC} / \mathrm{mm}^{3}\right)$. Cerebral arteriogram suggested vasculitis in only one of four cases. Diagnosis was made by brain biopsy in three cases and all three were treated successfully. The diagnosis in the two other cases was made at postmortem examination.

Granulomatous angiitis of the central nervous system is an uncommon necrotising vasculitis of unknown cause. ${ }^{1-3}$ Approximately 30 tissue-proven cases unassociated with Hodgkins's disease, ${ }^{45}$ or herpes zoster infections ${ }^{67}$ have been reported. Although good responses to steroids or immunosuppressive therapy have been described, the outcome is generally fatal. ${ }^{89}$ Moreover, in most cases, diagnosis was made only at necropsy, thus contributing to the apparent high fatality rate. We studied five tissue-proven cases unassociated with systemic illnesses which illustrate the varied manifestations of granulomatous angiitis.

\section{Case reports}

Case 1: For two months, a 69 year old man had a personality change with irritability and apathy. For 3 weeks, he had global headache, eye pain, and hesitancy in speech. Past history included a myocardial infarction and a coronary artery bypass grafting procedure. On examination, he was disoriented and apathetic with poor comprehension, jargon speech, mild right hemiparesis, bilateral grasp reflexes, and right Babinski sign. Laboratory studies showed a ESR 22

Address for reprint requests: Edward H Koo, M.D., Neuropathology Laboratory, The Johns Hopkins University School of Medicine, 509 Pathology Building, 600 North Wolfe Street, Baltimore, MD 21205, USA.

Received 21 January 1988

Accepted 15 April 1988 $\mathrm{mm} / \mathrm{h}$ and negative syphilis serology. CT showed a nonenhancing left temporoparietal mass. Arteriogram demonstrated elevation of the M1 segment consistent with mass effect but without tumour blush or segmental narrowing. A biopsy of the left temporal cortex showed extensive focal vasculitis involving the small penetrating and cortical arterioles and arteries up to $250 \mu \mathrm{m}$ in diameter. Small veins and venules were also involved. In this and other cases, the severity of inflammation often obliterated distinguishing landmarks between arteries and veins. The meninges were mildly inflamed with minor vasculitic changes in small pial vessels. The inflammatory infiltrate consisted of lymphocytes, histiocytes, and epithelioid cells which tended to disrupt the vessel walls (fig 1). Rare giant cells were present. The lesions were often transmural but segmental sparing of the endothelium, intima, or inner media were observed. Some vessels showed concentric or patchy proliferation of the endothelium. Special strains for bacteria, fungi, and acid-fast microorganisms were negative in all cases of this report. He was treated with prednisone $(80 \mathrm{mg} / \mathrm{day})$ and cyclophosphamide $(2 \mathrm{mg} / \mathrm{kg})$, the latter discontinued due to persistent leukopenia. CT at 3 months showed resolution of the previous mass with bilateral leukoencephalomalacia in the parieto-occipital areas. Four months after diagnosis, examination was normal and prednisone dosage was reduced. One year after the onset, while still taking prednisone $(5 \mathrm{mg}$ on alternate days), he complained of new headache. CT demonstrated a new low density lesion in the tip of the right temporal lobe. MRI confirmed the CT finding with an area of high signal intensity in the right temporal tip but in addition, similar lesions were seen in multiple areas of both hemispheres consistent with recent infarction (fig 2). After cholecystectomy, prednisone $(80 \mathrm{mg} /$ day $)$ was restarted and 


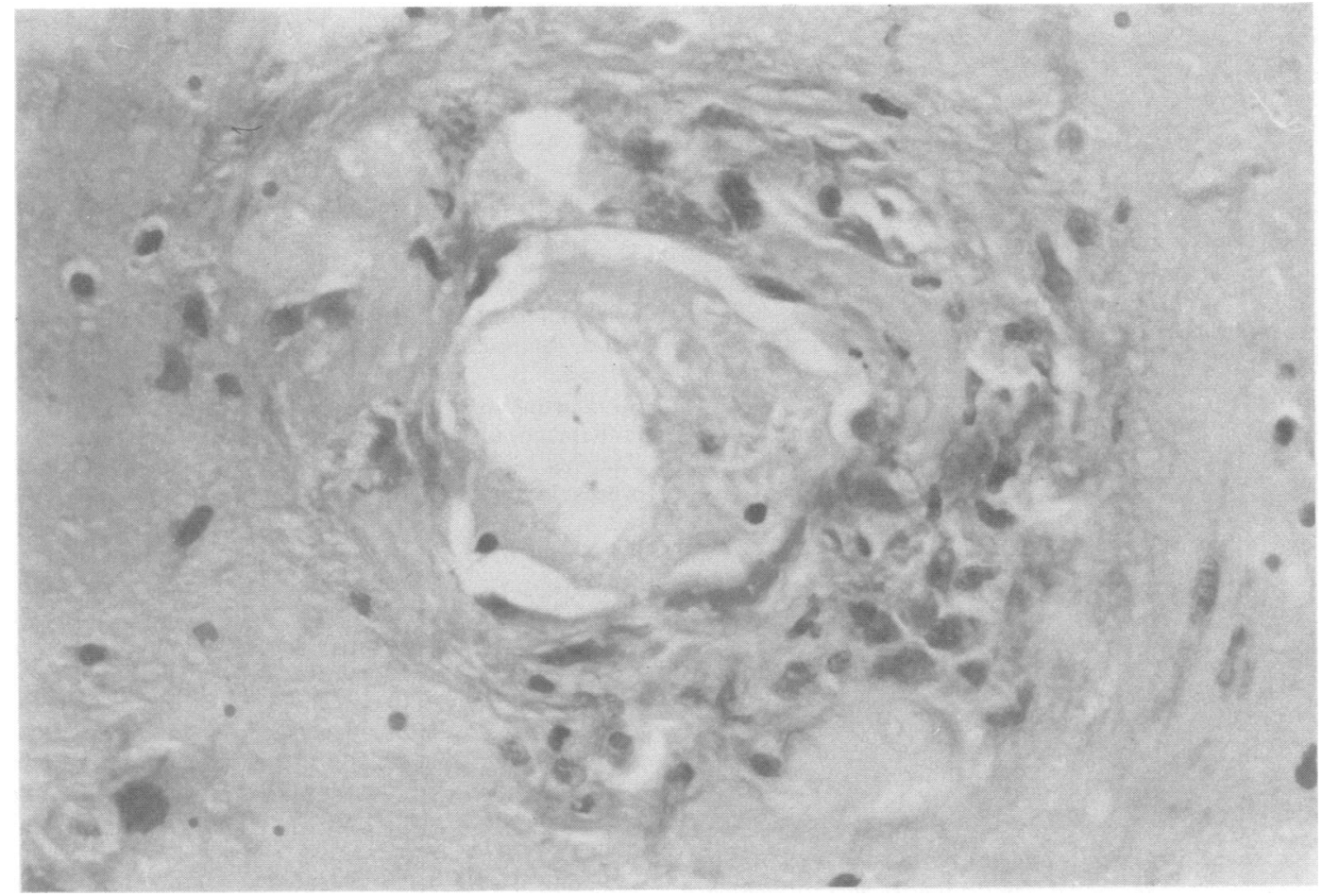

Fig 1 Microscopic section from case 1 shows a small cortical vessel with its wall infiltrated by a proliferation of lymphocytes, histiocytes, and epithelioid cells. $(H \& E ; \times 1100)$

his headache subsided. He remained symptom free on follow-up.

Case 2: For 6 weeks, a 65 year old man had progressive confusion and memory loss. His past history included coronary artery disease and mild glucose intolerance. Examination demonstrated waxing and waning disorientation and prominent frontal release signs. Laboratory studies included ESR $30 \mathrm{~mm} / \mathrm{h}$, normal thyroid functions, $B_{12}$, syphilis serology, and rheumatological screens. CSF pressure was 180 $\mathrm{mm} \mathrm{H}_{2} \mathrm{O}$, with $12 \mathrm{WBC} / \mathrm{mm}^{3}(8 \mathrm{~L}, 4 \mathrm{P})$, protein $142 \mathrm{gm} / \mathrm{l}$, glucose $76 \mathrm{gm} / 1$. CSF cultures and cytologies were negative. On serial CSF examinations, there were between 20 to 50 $\mathrm{WBC} / \mathrm{mm}^{3}$, primarily lymphocytes, and protein of 146 to $193 \mathrm{gm} / \mathrm{l}$. A cerebral angiogram was normal. CT showed mild cortical atrophy and a right posterior frontal lobe density consistent with infarct. A right inferior frontal meningeal biopsy showed diffuse vasculitis in the small meningeal vessels. The inflammation consisted of perivascular and intramural infiltration of lymphocytes and histiocytic cells. Patchy endothelial proliferation and scattered giant cells were present. Fibrinoid necrosis was not seen. Treatment with prednisone $(100 \mathrm{mg} /$ day $)$ was begun. Follow-up lumbar puncture one month later revealed 8 $\mathrm{WBC} / \mathrm{mm}^{3}$ and protein $43 \mathrm{gm} / \mathrm{l}$. The patient continued to improve and at 3 months, a tapering dose of steroid was instituted. At 18 months, his cognition was normal.

Case 3: A 44 year old man had a 2 week history of malaise and fever. One week before admission, he noted headaches, vomiting, and became disoriented. There was a remote history of alcohol abuse and hypertension. On examination, temperature was $39^{\circ} \mathrm{C}$. He was lethargic and oriented to his name only. Several small lymph nodes were palpable. His speech was mildly dysarthric. Plantar response was flexor bilaterally. Laboratory data included ESR $41 \mathrm{~mm} / \mathrm{h}$, WBC $11,600 / \mathrm{mm}^{3}$ (75 P, $\left.7 \mathrm{~B}, 11 \mathrm{~L}, 7 \mathrm{M}\right)$. CSF pressure was $245 \mathrm{~mm} \mathrm{H}_{2} \mathrm{O}$ with xanthochromia, $\mathrm{RBC} 3,000 / \mathrm{mm}^{3}$, WBC $800 / \mathrm{mm}^{3}(8 \% \mathrm{P}, 92 \% \mathrm{~L})$, glucose $39 \mathrm{mg} / \mathrm{dl}$ (serum 101 $\mathrm{mg} / \mathrm{dl}$ ), protein $119 \mathrm{mg} / \mathrm{dl}$ and gamma globulin $14 \%$ of total protein. CSF gram stain, cultures, and VDRL were all negative. He was treated for presumed meningitis. Several days later, while still febrile and disoriented, examination showed mild expressive aphasia, right hemiparesis, bilateral Babinski signs, and grasp reflexes. CT showed a hyperdense lesion in the left temporal lobe with surrounding low density areas consistent with haemorrhage. He was given ara-A for presumed herpes simplex encephalitis. Arteriogram revealed diffuse saccular and fusiform dilatations of small intracranial arteries in both hemispheres. A biopsy of the left temporal cortex without meninges showed intramural and perivascular inflammation of a small artery, measuring less than one millimetre in diameter. The infiltrate consisted of lymphocytes, histiocytes, and multinucleated giant cells. The vessel was thrombosed. The internal elastic lamina was intact without fibrinoid necrosis. There was no evidence of encephalitis and intracellular inclusions were not seen. A renal and mesenteric arteriogram was negative as were the 


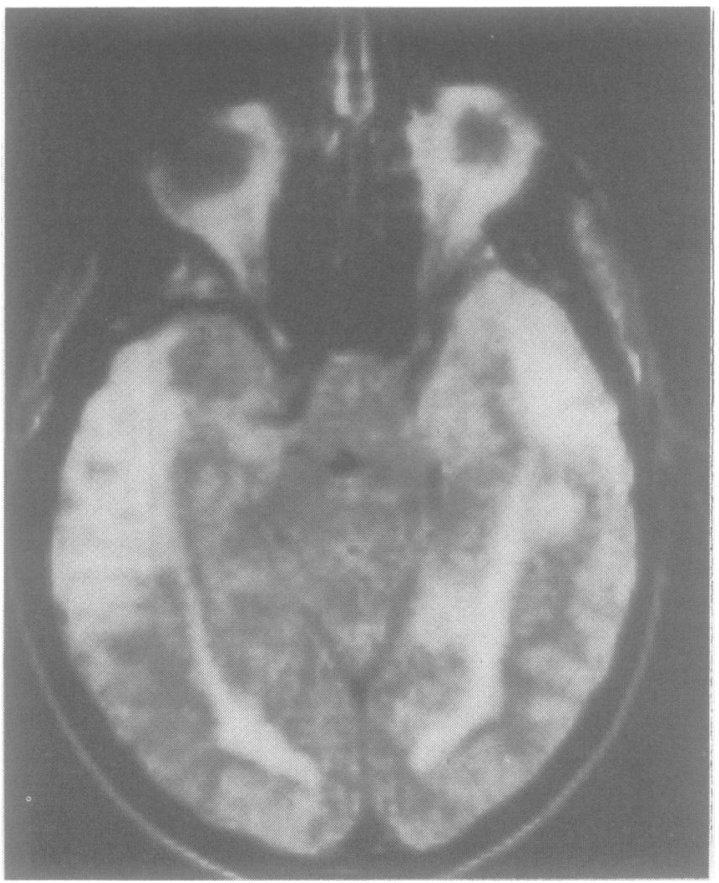

Fig 2 Magnetic resonance imaging of case 1 demonstrates multifocal areas of increased signal intensity on $T_{2}$-weighted spin-echo image, most marked in both temporal lobes.

rheumatological screens. The patient was treated with prednisone $(80 \mathrm{mg} /$ day) and cyclophosphamide $(2 \mathrm{mg} / \mathrm{kg})$ with gradual but not total improvement in his mentation. A repeat arteriogram 2 months later showed resolution of the previous abnormalities. CSF pressure was normal with WBC $6 / \mathrm{mm}^{3}$, protein $42 \mathrm{gm} / 1$, glucose $62 \mathrm{gm} / 1$, and gamma globulin $8.3 \%$ of total protein. He was discharged taking prednisone (5 mg/day) and cyclophosphamide $(75 \mathrm{mg} /$ day). Six months later, he stopped taking medication and was lost to follow-up. Two years later, he was readmitted after 2 days of left-sided weakness and disorientation. CT showed mild cortical atrophy with a small lucency in the left thalamus. Arteriogram showed narrowing of right internal carotid artery in supraclinoid region. Between 4 to 8 monocytes $/ \mathrm{mm}^{3}$ were seen in the CSF with protein from 56 to $63 \mathrm{gm} / 1$ and normal glucose. He was again given cyclophosphamide and prednisone. CSF two months later demonstrated no white cells but a protein of $76 \mathrm{gm} / \mathrm{l}$. Steroid dosage was tapered after 3 months while cyclophosphamide was continued for approximately a year. When last seen, he remained somewhat abulic but was otherwise fully oriented. A mild left hemiparesis persisted with diffusely brisk reflexes, bilateral extensor plantar responses and active frontal release signs. Case 4: A 78 year old man was found unresponsive on the floor. He had been in good health without complaints. A major motor seizure was witnessed. Examination showed disorientation with a left homonymous hemianopsia, left hemiparesis, minimal left hyperreflexia, bilateral extensor plantar responses, and frontal release signs. Laboratory studies included ESR $47 \mathrm{~mm} / \mathrm{h}$, normal $B_{12}$, thyroid functions, and syphilis serology. CSF showed normal opening pressure, no cells, glucose $115 \mathrm{gm} / 1$, and protein $81 \mathrm{gm} / 1$ with negative cultures, VDRL, and oligoclonal band. CT demonstrated bifrontal white matter hypodensities without enhancement, more on the right (fig 3). His mental status waxed and waned, but he remained depressed and abulic. The clinical diagnosis was multi-infarct state. Repeat lumbar puncture was remarkable only for a protein of $64 \mathrm{gm} / 1$. Two weeks later, he died after aspiration and cardiopulmonary arrest. At necropsy, the gyri over both hemispheres were flattened. Large vessels were minimally atherosclerotic. Marked angiitis of arterioles and small arteries up to $300 \mu \mathrm{m}$ in diameter, and to a lesser extent, veins and venules, were observed in both frontal and right occipital cortices. This process favoured smaller vessels to the extent that larger vessels adjacent to an involved arteriole or venule would be spared (fig 4). The vasculitis was most prominent in pial and penetrating vessels. Deeper vessels in the white matter were spared but patchy areas of ischaemic changes with reactive astrocytosis were observed. Other regions of the brain, large cerebral vessels, and systemic organs were not involved. The inflammation consisted of histiocytes and lymphocytes with scattered haemosiderin-laden macrophages and occasional multinucleated giant cells in the periphery. The inflammatory aggregates were often concentrically positioned about the vessels but segmental involvement was not uncommon. In many smaller vessels, PTAH stain showed prominent fibrinoid necrosis. These vessels were notable for a variable degree of inflammation and by the presence of scattered

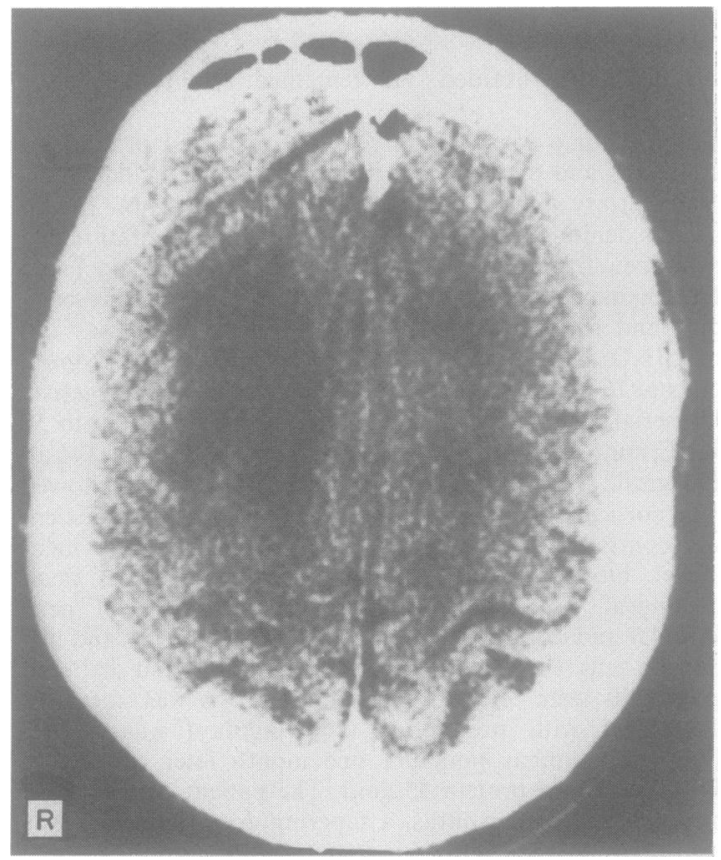

Fig 3 Bilateral white matter lucencies in the centrum semiovale are seen in the CT scan from case 4. 
neutrophils (fig 4). Endothelial proliferation was pronounced in some vessels. Perivascular ring haemorrhages and necrotic cellular debris were present in the superficial cortical regions. The meninges showed mild fibrosis.

Case 5: A 60 year old diabetic man had a several month history of falling and difficulty in walking. On examination, there was mild memory impairment, right hemiparesis and truncal ataxia. CT revealed minimal cortical atrophy. One month later, CT showed a low density area in the right cerebellum consistent with infarct. Signs included depressed mentation, dysmetric ocular movements, ataxic limbs, and right Babinski sign. ESR was $28 \mathrm{~mm} / \mathrm{h}$ and ANA was negative. CSF contained between 30 to $169 \mathrm{WBC} / \mathrm{mm}^{3}(100 \%$ L), protein about $100 \mathrm{gm} / 1$, normal glucose, pressure of 330 mm $\mathrm{H}_{2} \mathrm{O}$ with negative cytology and cultures. $\mathrm{CT}$ suggested bilateral low density areas deep in the cerebellum. An arteriogram was normal. Prednisone $(100 \mathrm{mg} /$ day $)$ and radiation therapy were given for presumed cerebellar glioma. After 2 weeks, he showed mild improvement together with a decrease in CSF pleocytosis (2 WBC/ $\mathrm{mm}^{3}$ ) and protein (31 $\mathrm{gm} / \mathrm{l}$ ) but died 2 weeks later from complications of a perforated appendix. At postmortem examination, there was minimal atherosclerosis of the large vessels. The right cerebellar hemisphere was soft, with loss of cytoarchitecture and a brown discolouration consistent with subacute infarct. Smaller foci of softening were present in the base of the pons. Microscopically, striking granulomatous angiitis was present in small leptomeningeal vessels in the cerebellum and, to a lesser extent, the brainstem. Arterioles and arteries, up to one millimetre in diameter, and veins were affected. The process was widespread, but in less involved areas, the angiitis clearly favoured the meningeal and penetrating vessels over the parenchymal ones (fig 5). The transmural inflammation consisted of infiltration of lymphocytes, histiocytes, and multinucleated giant cells, concentrically or segmentally extending to or beyond the borders of the adventitia (fig 6). In the periphery, fibroblasts and lymphocytes, admixed with scattered haemosiderin-laden macrophages, predominated. Many vessels were partially or totally occluded by the proliferation of endothelium, fibroblasts, and inflammatory cells. Features of chronic ischaemia with marked rarefaction, neuronal loss, and gliosis were evident in much of the cerebellum. From the upper cervical cord to the midbrain, minor vasculitic changes were observed. Lymphocytic infiltration was more intense than the fibroblastic response in these vessels, while the ischaemic changes were more recent than in the cerebellum. Additional small foci were present in the hypothalamus, optic chiasm, and gyrus rectus. The eye and systemic organs were spared.

\section{Discussion}

Granulomatous angiitis is a rare disorder presenting in adults with necrotising inflammation of small cere-

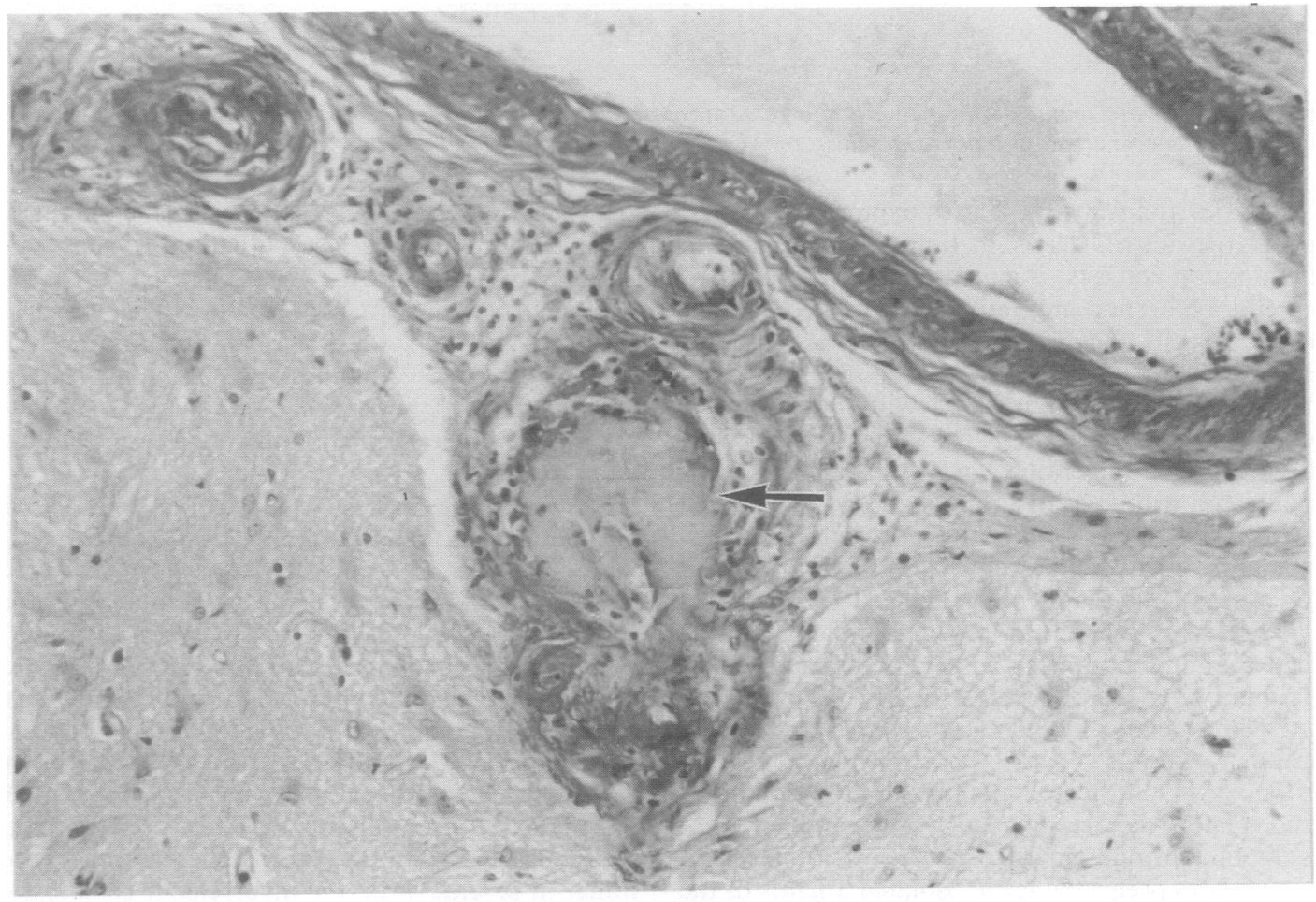

Fig 4 Fibrinoid necrosis is evident in this small pial vessel from case 4 (arrow). The predeliction for small vessels is underscored by the sparing of an adjacent large vessel situated in the upper right corner of this photomicrograph. (H\&E; $\times 400$ ) 


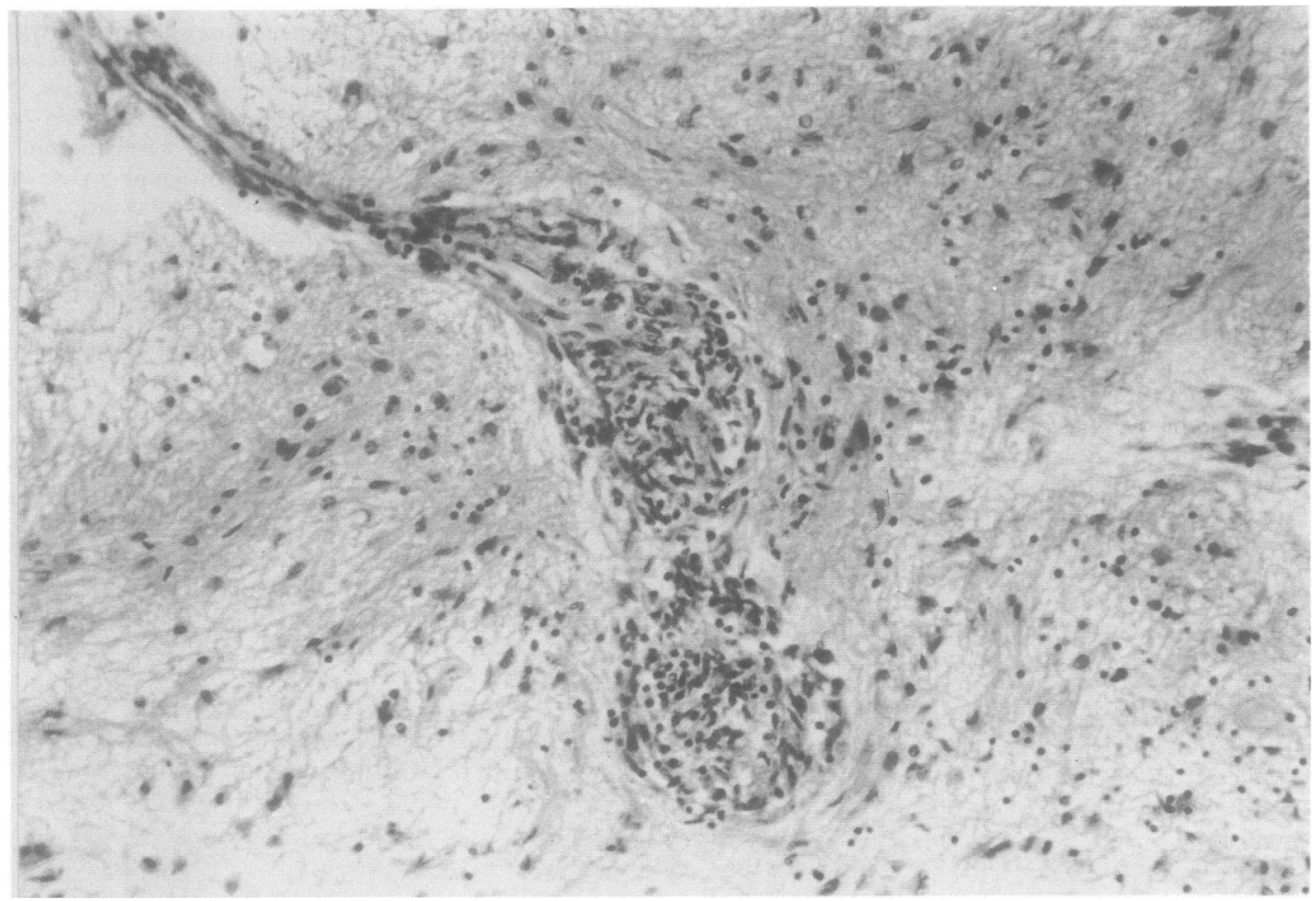

Fig 5 . The segmental nature of the angiitis is illustrated in case 5 by the nodular aggregations of inflammatory cells along this small leptomeningeal artery as it penetrates the rarefied and gliotic cerebellar cortex. $(H \& E ; \times 300)$

bral arteries and veins ${ }^{29-20}$ with diameter about 200 $\mu \mathrm{m} .{ }^{1}$ Larger vessels may sometimes be involved. The inflammation consists of macrophages, lymphocytes, epithelioid cells, and multinucleated giant cells within the vessel walls and may be associated acutely with fibrinoid necrosis ${ }^{210}$ and polymorphonuclear leukocytes. Eosinophils and necrosis within granulomas are generally absent. In early cases, lymphocytes infiltrate in the adventitia, ${ }^{1}$ while in chronic cases, fibroblastic proliferation may become prominent (case 5). There is a predilection for leptomeningeal over the parenchymal vessels ${ }^{12}$ and the involvement may be segmental, patchy, or diffuse. ${ }^{11}$ Blood vessels in any part of the central nervous system may be affected $^{91}$ and, occasionally, the disease may be predominantly venous, ${ }^{16}$ meningeal, or even ventricular. ${ }^{22}$ Rarely, clinically silent lesions have been seen in visceral organs at postmortem examination. ${ }^{211122122}$ Occasionally, the granulomatous nature of this disease may only be a minimal component of the inflammatory process. ${ }^{26}$ As a result, some authors prefer the term "isolated angiitis of the nervous system" to emphasise its unique distribution rather than the histological features. ${ }^{26}$ Ischaemic necrosis, haemorrhagic infarcts in evolving stages, and reactive astrocytosis are generally observed in the surrounding brain tissue. ${ }^{12}$ The aetiology and pathogenesis are unknown, but particles resembling mycoplasma ${ }^{23}$ or viral-like structures ${ }^{24}$ have been described. Detailed studies of vessel immunoreactivity, as done in other systemic vasculitides, are lacking. Immunoperoxidase studies in one case did not detect the presence of immunoglobulin deposition within the vessel walls. ${ }^{25}$

It has not been possible to categorise definitively granulomatous angiitis among the inflammatory vasculitides: whether this disease is a separate entity and distinct from the other systemic vasculitis which affect the central nervous system is uncertain. The major differential diagnoses include the systemic arteritides such as periarteritis nodosa, rheumatoid arteritis, lymphomatoid granulomatosis, Takayasu's disease, and temporal arteritis, sarcoidosis, infectious angiitis, especially herpes zoster, and granulomatous angiitis associated with Hodgkin's disease. At present, it is distinguished from the other inflammatory vasculitides in several ways: the involvement is almost exclusively in the central nervous system with absence of systemic signs, ${ }^{26}$ the lesions affect not only small arteries but also veins, ${ }^{12}$ the vessels involved are smaller, 


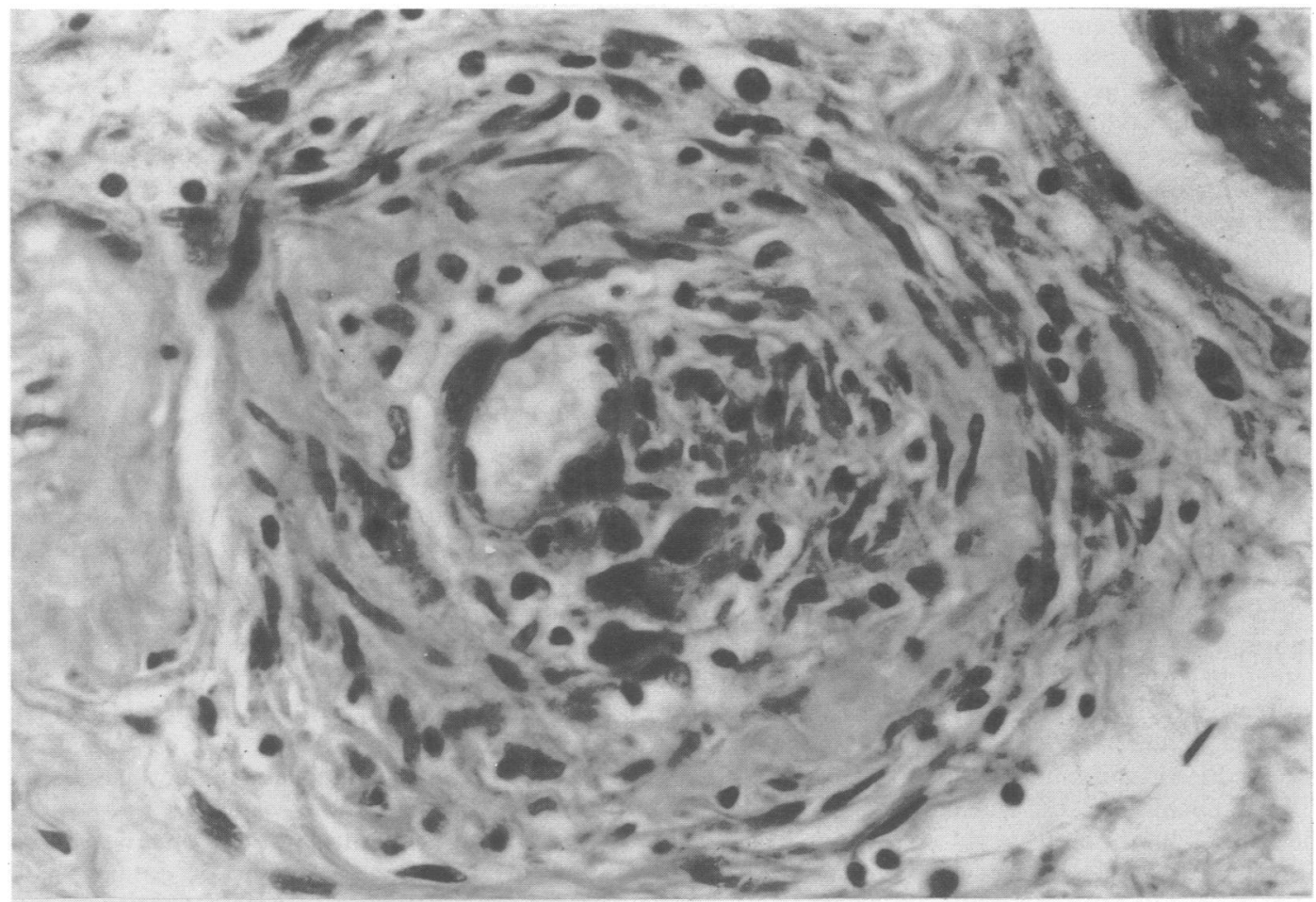

Fig 6 Microscopic section from case 5 shows extensive involvement of a leptomeningeal vessel with proliferation of mononuclear and epithelioid cells surrounded by a rim of lymphocytes and fibroblasts in the periphery. $(H \& E ; \times 1000)$.

the inflammation tends to be less necrotising in character, ${ }^{11}$ and eosinophils are absent. ${ }^{10}$ Granulomatous angiitis is separated from sarcoidosis by the general absence of necrosis in the latter, the prominent perithelial granulomas, a greater tendency to involve the base of the brain, and the involvement of systemic organs. ${ }^{11}$ The pathology may be inseparable from herpetic angiitis. ${ }^{6727}$ The distinction then lies in the invariable antecedent herpetic eruption, often in the ophthalmic division of the trigeminal nerve with resultant contralateral hemiparesis. Some authors consider this disease to be a variant of temporal arteritis. ${ }^{1028}$ However, even though there have been rare cases where the vasculitis involved both the temporal and intracranial arteries, ${ }^{2930}$ granulomatous angiitis is generally considered to be distinct from temporal arteritis. $^{311}$ The latter tends to involve older patients, is frequently coincidental with polymyalgia rheumatica, and the sedimentation rate is strikingly elevated. ${ }^{3}$ Anatomically, the lesions of temporal arteritis involve larger arteries while sparing the intracranial arteries and veins, and are not characterised by the prominent granulomatous response. ${ }^{1131}$ While not absolute, these clinicopathologic features, taken together, define a characteristic entity. Our five cases all share features of a chronic necrotising vasculitis involving small cerebral vessels and lack evidence of an underlying systemic vasculitis. Although the intensity of the lesions varied, the changes generally correlated with the duration of neurological symptoms.

The clinical manifestations are chiefly neurological and no consistent clinical pattern suggests the diagnosis. Non-specific manifestations include weight loss, malaise, headache, vomiting, visual loss, confusion,

Table Comparison of laboratory values between present series and tissue-proven cases in the literature

\begin{tabular}{llc}
\hline & Present series & Literature* $^{*}$ \\
\hline ESR ( $>30 \mathrm{~mm} / \mathrm{hr})$ & $2 / 4$ & $6 / 19$ \\
CSF opening pressure & $2 / 3$ & $6 / 18$ \\
$\left(>220 \mathrm{mmH}_{2} \mathrm{O}\right)$ & $3 / 4$ & $19 / 24$ \\
CSF WBC $\left(>5 / \mathrm{mm}^{3}\right)$ & $4 / 4$ & $19 / 26$ \\
CSF protein $(>45 \mathrm{gm} / 1)$ & $1 / 4$ & $5 / 19$ \\
CSF glucose $(<45 \mathrm{gm} / 1)$ & $4 / 4$ & $26 / 28$ \\
Any CSF abnormality & (OP, WBC, protein, glucose) & $4 / 4$ \\
\hline
\end{tabular}

*Tabulated from ref. 1, 2, 9-26, 34-36; but does not include the following cases: ref. 1 , case 4 (herpes zoster ophthalmicus), ref. 10, cases 1, 2 (temporal arteritis), ref. 17, case 2 (Churg-Strauss), ref. 26, cases 1, 2, 3 (no tissue diagnosis). 
and lethargy. Systemic symptoms, such as arthalgia, myalgia, or skin rash, are absent. Focal signs of hemiparesis, aphasia, myelopathy, or seizures, are present at some point in the clinical course. In addition, signs of increased intracranial pressure and encephalopathy are common. A stepwise progression or multifocal signs point towards a vasculitis. But these characteristic findings are frequently absent in the early phases of the illness. Our cases emphasise the protean manifestations of this disease. Features of a progressive multifocal disorder were lacking and they mimicked stroke, tumour, or infection. The three cases (1,2 and 3) reported here with long term survival suggests clinical remission may be achieved with early diagnosis and treatment.

In diagnosing this disease, routine laboratory studies including rheumatological screens are uniformly unrevealing. ${ }^{26}$ The erythrocyte sedimentation rate is often normal (table). The CSF is almost always abnormal with mononuclear pleocytosis and high protein, as in our cases. In addition, CSF pressure is often increased while hypoglycorrhachia ${ }^{24} 26$ or xanthochromia, ${ }^{291224}$ as in Case 3, is infrequent. Increased CSF gamma globulin ${ }^{1025}$ has been noted while oligoclonal bands have not been described. The CSF abnormalities can resolve with clinical improvement.

The diagnosis cannot definitively be made by cerebral angiography despite claims to the contrary. ${ }^{32}$ One quarter of the tissue-proven cases had normal studies, ${ }^{9101323}$ while $50 \%$ showed non-specific arterial narrowing, ${ }^{11921-23253334}$ and only $25 \%$ demonstrated segmental narrowing or beading. ${ }^{11} 142035$ In the latter group, angiograms of two patients were non-diagnostic at first and were abnormal on a second study. ${ }^{1135}$ Angiographic changes in cases not supported by tissue diagnosis are of uncertain value. ${ }^{2632}$ In a case of "benign cerebral vasculitis" biopsy of an angiographically abnormal vessel was unremarkable. ${ }^{36}$ In our cases, angiography was normal in cases 2 and 5; and showed only mass effect in case 1 . In case 3 , irregular dilatations resolved with treatment.

CT abnormalities were seen in all of our five patients. However, these changes were nonspecific, with areas of low density, mass effect, or cortical atrophy. Lesions consistent with haemorrhagic infarction can also be seen (case 3). Similar abnormalities were described in five of seven reported cases with CT. ${ }^{142122} 2534$ In case 4, CT showed bilateral white matter hypodensities suggesting early infarction (fig 3). Similar white matter lucency was described in two other cases, ${ }^{1422}$ and one case associated with Hodgkin's disease. ${ }^{5}$ This feature offers a clue to the diagnosis because of the multifocal lesions that do not conform to major vascular territories. CT findings may similarly subside (cases 1 and 3).

Brain biopsy has been advocated when the angiogram is negative. ${ }^{1126}$ The present series probably skews the emphasis towards the need for biopsy since pathological confirmation was required for inclusion into this study. However, of the three premortem diagnoses, the diagnosis was suggested by the angiogram in only case 3 . The remaining two cases ( 1 and 2) still required a biopsy. Thus, this study reaffirms a position held by some authors for the need to proceed to brain biopsy for definitive diagnosis, especially when the arteriogram is unrevealing. ${ }^{26}$

Among reported cases, diagnosis was established by biopsy in seven $1920252633-35$ but not in 10 others. ${ }^{191315-182223}$ The patchy nature of this disease may account for the low yield of open biopsy. However, many of the negative cases were from the early reports when the disease was less well known. Temporal artery biopsy is uniformly negative ${ }^{2335}$ and thus should not be routinely pursued. One biopsy was abnormal ${ }^{10}$ (case 1 of ref.) but the case more accurately fits a diagnosis of temporal arteritis. To maximise the yield on biopsy, it is imperative to obtain both leptomeningeal and cortical tissue for pathological examination. ${ }^{8}$

Although a generally fatal outcome was described in earlier cases, ${ }^{1121315-17}$ several patients have recovered or survived. Specifically, of the tissue-proven cases, apparent spontaneous improvement was reported in two patients, ${ }^{2533}$ their only treatment being five days of tapering doses of dexamethasone given as part of the biopsy procedure. Four cases improved or stabilised on corticosteroids, ${ }^{191920}$ while two additional cases responded to steroid and cytotoxic drugs, either azothioprine ${ }^{35}$ or cyclophosphamide. ${ }^{26}$ However, the remission was not sustained in four of the six cases. ${ }^{191935}$ The time course in those cases was unpredictable. Brief trials of corticosteroids in the antemortem period did not alter the outcome in five other cases. ${ }^{10} 142123$ In two patients with Hodgkin's disease, the neurological signs remitted following treatment of the malignancy. ${ }^{45}$ In our three treated patients, the responses have been satisfactory. Case 1 had asymptomatic involvement of the contralateral hemisphere detected by CT and MRI and case 3 relapsed while off medication but stabilised with reinstitution of treatment. These cases suggest that even with early response, prolonged treatment is indicated. Furthermore, the fluctuating courses in cases 1 and 3 suggest that follow-up might include CT or lumbar puncture to diagnose early relapse. In anecdotal reports, high dose steroid was the drug of choice while additional benefits from immunosuppressive agents such as cyclophosphamide may be seen. While adequate clinical trials are lacking, the outcome in those patients given steroids appears to be better than 
no treatment. Whether immunosuppressive drugs should be added routinely is uncertain. In view of the likelihood of an extended period of treatment with potentially hazardous drugs, the need to establish an unequivocal diagnosis is of utmost importance.

We are grateful to Dr $\mathbf{R}$ Young for referring case one and to Dr M V Solbrig for her assistance with cases 1 and 4.

\section{References}

1 Kolodny EH, Rebeiz JJ, Caviness VS, Richardson EP. Granulomatous angiitis of the central nervous system. Arch Neurol 1968;19:510-24.

2 Nurick S, Blackwood W, Mair WGP. Giant cell granulomatous angiitis of the central nervous system. Brain 1972;95:133-42.

3 Moore PM, Cupps TR. Neurological complications of vasculitis. Ann Neurol 1983;14:155-67.

4 Rajjoub RK, Wood JH, Ommaya AK. Granulomatous angiitis of the brain: a successfully treated case. Neurology 1977;27: 588-91.

5 Greco FA, Kolins J, Rajjoub RK, Brereton HD. Hodgkins's disease and granulomatous angiitis of the central nervous system. Cancer 1976;38:2027-32.

6 Linnemann CC, Alvira MM. Pathogenesis of varicella-zoster angiitis in the CNS. Arch Neurol 1980;37:239-40.

7 DeReuck J, Crevits L, Sieben G, De Coster W, vander Eecken H. Granulomatous angiitis of the nervous system: a clinicopathological study of one case. $J$ Neurol 1982;227:49-53.

8 Vincent FM. Granulomatous Angiitis. N Engl J Med 1977; 296:452.

9 Harrison PE. Granulomatous angiitis of the central nervous system. J Neurol Sci 1976;29:335-41.

10 Jellinger K. Giant cell granulomatous angiitis of the central nervous system. J Neurol 1977; 215:175-90.

11 Burger PC, Burch JG, Vogel FS. Granulomatous angiitis: an unusual etiology of stroke. Stroke 1977;8:29-35.

12 Cravioto H, Feigin I. Noninfectious granulomatous angiitis with a predilection for the nervous system. Neurology 1959;9: 599-609.

13 Hughes JT, Brownell B. Granulomatous giant-celled angiitis of the central nervous system. Neurology 1966;16:293-8.

14 Faer MJ, Mead JH, Lynch RD. Cerebral granulomatous angiitis: case report and literature review. AJR 1977;129:463-7.

15 McCormick HM, Neubuerger KT. Giant cell arteritis involving small meningeal and intracerebral vessels. J Neuropathol Exp Neurol 1958;17:471-8.

16 Budzilovich GN, Feigin I, Siegel H. Granulomatous angiitis of the nervous system. Arch Pathol 1963;76:250-6.

17 Newman W, Wolf A. Non-infectious granulomatous angiitis in- volving the central nervous system. Trans Am Neurol Assoc 1952;77:114-7.

18 Sandhu R, Alexander WS, Hornabrook RW, Stehbens WE. Granulomatous angiitis of the CNS. Arch Neurol 1979;36: 433-5.

19 Rewcastle NB, Tom MI. Non-infectious granulomatous angiitis of the nervous system associated with Hodgkin's disease. $J$ Neurol Neurosurg Psychiatry 1962;25:51-8.

20 Case records of the Massachusetts General Hospital (case 43-1976). N Engl J Med 1976;295:944-50.

21 Rawlinson DG, Braun CW. Granulomatous angiitis of the nervous system first seen as relapsing myelopathy. Arch Neurol 1981;38:129-31.

22 Reik L, Grunnet ML, Spencer RP, Donaldson JO. Granulomatous angiitis presenting as chronic meningitis and ventriculitis. Neurology 1983;33:1609-12.

23 Arthur G, Margolis G. Mycoplasma-like structures in granulomatous angiitis of the central nervous system. Arch Pathol Lab Med 1977;101:382-7.

24 Reyes MG, Fresco R, Chokroverty S, Salud EQ. Viruslike particles in granulomatous angiitis of the central nervous system. Neurology 1976;26:797-9.

25 Kristoferitsch W, Jellinger K, Bock F. Cerebral granulomatous angiitis with atypical features. $J$ Neurol 1984;231:38-42.

26 Cupps TR, Moore PM, Fauci AS. Isolated angiitis of the central nervous system. Am J Med 1983;74:97-105.

27 Hilt DC, Buchholz D, Krumholz A, Weiss H, Wolinsky JS. Herpes zoster ophthalmicus and delayed contralateral hemiparesis caused by cerebral angiitis: diagnosis and management approaches. Ann Neurol 1983;14:543-53.

28 Russi E, Aebi M, Kraus-Ruppert R, Mumenthaler M. Intracranial giant cell arteritis. $J$ Neurol 1979;221:219-24.

29 Goodwin JA. Temporal arteritis, In: Vinken PJ, Bruyn GW, Klawans HL (ed): Handbook of Clinical Neurology, vol 39. Amsterdam, North-Holland, 1980:313-42.

30 Kjeldsen MH, Reske-Nielsen E. Pathological changes of the central nervous system in giant cell arteritis. Acta Ophthalmol 1968;46:49-56.

31 Wilkinson IMS, Russell RWR. Arteries of the head and neck in giant cell arteritis. Arch Neurol 1972;27:378-91.

32 Craven RS, French JK. Isolated angiitis of the central nervous system. Ann Neurol 1985;18:263-5.

33 Beresford HR, Hyman RA, Sharer L. Self-limited granulomatous angiitis of the cerebellum. Ann Neurol 1979;5:490-2.

34 Valvanis A, Friede R, Schubiger O, Hayek J. Cerebral granulomatous angiitis simulating brain tumor. $J$ Comput Assist Tomogr 1979;3:536-8.

35 Griffin J, Price DL, Davis L, McKhann GM. Granulomatous angiitis of the central nervous system with aneurysms on multiple cerebral arteries. Trans Am Neurol Assoc 1973;98:145-8.

36 Serdaru M, Chiras J, Cujas M, Lhermitte F. Isolated benign cerebral vasculitis or migrainous vasospasm? J Neurol Neurosurg Psychiatry 1984;47:73-6. 